\title{
Attachment of Natural Lightning Flashes to Trees: Preliminary Statistical Characteristics
}

\author{
Jakke Mäkelä ${ }^{*}, 1$, Eero Karvinen ${ }^{2}$, Niko Porjo ${ }^{1}$, Antti Mäkelä ${ }^{3}$ and Tapio Tuomi ${ }^{3}$ \\ ${ }^{I}$ Nokia Oyj, Salo, Finland \\ ${ }^{2}$ Department of Chemistry, University of Jyväskylä, Finland \\ ${ }^{3}$ Finnish Meteorological Institute, Helsinki, Finland
}

\begin{abstract}
Lightning attachment to trees was studied based on 37 trees that were struck in Finland in summer 2007 and 2008. The type and severity of lightning damage was correlated with multiple parameters related to the flash, the meteorological characteristics of the strike time, and the surroundings of the tree. Damage was classified into three categories: bark-loss (minor), wood-loss (extensive), end explosive (complete loss of tree material). Four statistically significant parameters were found. The absolute value of the peak flash current is strongly correlated with damage; also, an indirect argument suggests that positive flashes cause more damage than negative flashes. The amount of damage is inversely correlated with the rainfall in the previous three hours, indicating that a wet ground and tree surface protect trees against damage by providing a conducting path to the ground. The ground type also has a weaker statistically significant effect, with poorly conducting ground leading to more extensive damage. Old and rotten trees are statistically most likely to experience explosive damage. Other parameters are inconclusive. The distribution of tree heights points to the possibility that the electrogeometric method does not necessarily predict the strike probability to a given tree. In many cases, the struck trees were clearly within the protective radius of a higher structure, although this is often difficult to determine from photographs. It is therefore suggested that models of lightning flashes to trees should include both the conductivity and height of the tree. The results may be significant for remote prediction of lightning damage, as well as for understanding lightning protection of structures which include trees.
\end{abstract}

Keywords: Lightning attachment, tree damage, lightning location, observations, lightning protection.

\section{INTRODUCTION}

Flashes to trees are one way to study attachment processes in natural lightning. A flash leaves a physical record in the ground and the surface of the tree. Trees therefore afford a unique possibility for studying the very fine structure of lightning attachment. If the flash parameters and meteorological conditions are known, patterns may be found. Most books on lightning physics and lightning protection include chapters on lightning and trees [1-4]. However, in general the literature is fragmented and to a large extent relies on individual case studies. Tree damage is known to be highly variable. In [5], a lightning flash to a wet European ash tree was observed that caused no discernible damage at all. At the other extreme, there are many individual case studies of flashes which have essentially exploded whole trees. These case studies mostly date from the 1920's [6,7], but there is also one recent study [8]. An intermediate type of damage are vertical scars on the trees described for a single case study by [9] and an extensive statistical study of damage to pine trees by [10]. It is briefly mentioned in [11] that lightning may strike isolated tree stubs left after forest fires, but no other mentions of this type

*Address correspondence to this author at the Nokia Oyj, P.O. Box 86, 24101 Salo, Finland; Tel: +358-50-3663418;

E-mails: Jakke.Makela@nokia.com, Jakke.Makela@gmail.com of damage are known from the literature. In [3] (section 18.4.2) it is noted that there are variations in the damage mechanism between tree types, with rough-barked conifers (evergreens) usually showing scar-type damage, while smooth-barked species such as birches (with a transverse grain structure) can have their bark torn off in irregular patches.

Lightning damage can be analyzed from at least two perspectives, called macroscale and microscale by [2]. The macroscale essentially looks at the tree as a structure, without analyzing chemical or structural changes in the wood material. Microscale effects refer to the chemical and physical changes in the material itself. Although such a division is to some extent arbitrary and is not rigidly followed in the literature, it could be useful in planning future research. Microscale effects are effectively those which could be simulated (at least to some accuracy) in the laboratory. Macroscale effects, on the other hand, can only be studied in real natural conditions. Our study focuses purely on macroscale effects.

There are several methods for collecting information on lightning flashes to trees. In the statistical method of [10], large tracts of forest are scanned for lightning damage. The study of [12] and references therein collected data somewhat less systematically. This allows a large data set, but without the possibility for correlating the damage with flash and 
meteorological parameters. [10] studied one thousand evergreens (Douglas firs) in Montana, of which 10 (1\%) had been completely demolished, about $100(10 \%)$ had severed tops, about $250(25 \%)$ had multiple scars, and the great majority $(64 \%)$ had a single vertical scar. This suggests that severe damage is a very rare occurrence. On the other hand, the method of [10] will completely miss cases in which there is no damage at all (e.g. the single tree in [5]), and most likely would also be unable to identify unusual cases such as damage to tree stumps (observed in [11]). There is also an observer effect, in that observers are more likely to see damage that is extreme and also in conformance with the type of damage they expect to see. For example, at least in tropical forests [13], note that lightning damage may be difficult to identify, since many cases do not conform to the standard assumptions of lightning damage.

In the "case-study" method, media reports or other sources are used to find dramatic cases of tree damage; when the time and location are known, lightning and meteorological parameters can sometimes be back-traced (most successfully in [8] for two flashes). This method does not allow large data sets to be gathered easily. More problematically, it can create a bias in favor of dramatic effects; weak effects are likely to be underreported or not reported at all. Laboratory tests [14] allow all parameters to be controlled, but may or may not correspond to natural flashes. In 2007, we experimented with a different methodology, which could be called a "flash-based" method, described in Section 2. Our 2008 study conforms to the "case-study" methodology.

From a lightning protection viewpoint, the strike probability of a given tree is a parameter of interest. When evaluating the existing literature, it is important to note that strike probability and damage probability are not always clearly separated. For example, attempts to identify specific tree types most likely to be hit e.g. [12] are hampered by lack of information on the distribution of trees in the given forests as well as information on the height of the struck trees [1]. [15] suggests that such attempts are more likely to reflect the ability of some species to withstand lightning strikes without obvious external injury, rather than any variations is susceptibility to strikes.

There are very few papers on tree damage in the physics literature. Somewhat more attention has been paid to the biological and ecological effects of lightning damage to forests [13,16-18]. The overall ecological damage is often not limited to just the tree that has been struck, since the damaged tree can cause infestations of various types of insects that also damage surrounding trees. Especially in the tropics, lightning has been associated with damage to multiple trees, possibly as a result of such a mechanism. Our study does not address the biological effects, but on the physical inferences that can be drawn based on the tree damage.

Furthermore, this study does not address the detailed characteristics of the wood material. As noted in [10], the characteristics of the tree have a very great role in determining the damage mechanism. In almost all cases, the trees with the most severe damage were old, partially damaged trees. The implication is that the wood material in old trees is different from that of young trees. The response of wooden poles to current surges was studied under laboratory conditions by [19]. According to those experiments, the breakdown path is either completely internal or completely external, but generally not a combination. The exact pathway depends on many parameters. The most important is the moisture content of wood. If the wood material is dry (moisture $<20 \%$ ), the flash pathway tends to be external, while in wet wood (moisture $>50 \%$ ) it is always internal. Since no data on the tree moisture could be directly collected in this study, this information is difficult to correlate with the damage type. It is suggested by [8] that part of the difference could be due to voids and defects in the tree material, which could cause flashover and hence high heating. In general there are large variations in the electrical characteristics of different types of wood, and the resistivity of wood can vary over two orders of magnitude between seasoned and unseasoned wood poles [20]. The causative factor is the moisture content, which also depends on the air humidity and raininess and their history. [20] also note that the electrical properties of softwoods and hardwoods appear to be very similar.

Based in part on the older literature, we have identified the following hypotheses which are at least in principle falsifiable.

1. "The highest trees are most likely to be struck". [12] claims that trees which stand well above the neighboring trees are more vulnerable to lightning. This is in general a common-sense assumption, but does not take into consideration the possible interaction between conductivity and height. [15] suggests that this view may however be too simplistic.

2. "Trees growing in then open, either alone or in a small group, or at the edges of forests, are more likely to be struck". This was claimed by [12]. Since such isolated trees are more likely to be seen by casual observers, this results is definitely affected by observer effects. [12] also suggests that trees growing along avenues or in the border of woods more often struck by lightning. The observer effect is again likely to be severe in this case, with strikes inside dense forests likely to be unobserved.

3. "Tree surface and ground moisture affects the tree damage": [12] suggests that trees growing in moist soil are better conductors than other trees. The undamaged tree photographed by [5] had a surface and ground that was saturated with rain. A high conductivity and wet ground mean that the tree functions as a good downconductor for the lightning, and would therefore be more likely to be struck than an equivalent tree with higher resistance. On the other hand, wetness could also have the effect of making the surface of the tree the preferred current path rather than the interior of the tree, resulting in decreased damage to the wood material. Thus, even if strike probability were to increase, it is not a priori clear how the damage probability would be affected.

4. "Trees growing in poorly conducting ground are more likely to be damaged": According to [12], trees growing in loam or sandy soils are much more likely 
to be attacked by lightning than the trees in clay, marl, and calcareous soils. This result has not been verified in later studies. On the other hand, the Hummel equation as analyzed by [21] suggests that moisture variations should dominate over ground type variations. Hummel's equation for the resistivity is $\rho=(1.5 / p-0.5) \rho_{v}$, where $\rho_{v}$ is the resistivity of the water in the soil and $\mathrm{p}$ is the relative volume of the water in the soil. However, [21] estimates typical resistivities of about 25-70 $\Omega \mathrm{m}$ for clay, 50-250 $\Omega \mathrm{m}$ for cultivated soil, and 1000-3000 $\Omega \mathrm{m}$ for sand. Thus, ground type could be relevant for a large data set.

5. "Certain tree types are more likely to be struck than others". [12] claims that starchy trees are better conductors than oily trees, while conifer trees are intermediate. Although this may be the case, measurements by [22] show that the water content of the wood is by far the dominant characteristic determining the resistance, with resistance decreasing by four order of magnitude as the moisture content changes from $10 \%$ to $20 \%$. The moisture effect dominates over differences in wood species. It is not known how much the moisture content varies in living trees between species and different individual trees.

6. "Old trees are more likely to be damaged heavily". Sound trees in general are less likely to be seriously damaged than rotten wood, according to [12]. Similarly, [10] and [2] noted that explosive damage was confined almost entirely to very old and very large trees, possibly due to internal defects and voids along which the flashover can occur more easily. Alternatively, the moisture content of partially rotting trees may be large enough to result in a predominantly internal pathway as described by [19]. The exploded trees analyzed by [8] were exceptionally large and therefore old, although the quality of the trees is not known.

7. "The presence of a good electrical ground will affect tree damage". If the complete path of the current is considered, there could be a difference between a case where the current is quickly grounded in a structure like a well and one in which there is no clear earthing point. Also, the manner in which the tree's roots are grounded will affect the lightning path. No single parameter models this effect well, but as a proxy we have used the presence of large bodies of water near the flash site. The hypothesis is that there will be a difference between trees located next to a body of water and one that is not, although the exact damage cannot be predicted. This grounding idea was extended to include electrical wires or underground cables; since many of the cases were in inhabited areas, the termination of the flash in an electrical circuit could often be seen from damage to buildings' electrical appliances.

8. "Continuing currents cause most damage". Laboratory tests by [14] showed that a continuous current significantly increases ignition, but even an impulsive current can cause ignition. Also, [23] show that at least for forest fires in Finland, continuing currents are not necessary. Our collection methodology does not allow us to estimate continuing currents directly, but some estimates can be made. As observed by [24], high multiplicity means a high probability of a continuing current. Similarly, high positive currents tend to imply continuing currents [8]. Continuing current must therefore be estimated indirectly; however, if very large damage were correlated strongly with high multiplicity, this would suggest a connection.

9. "Strong positive flashes cause more damage". [8] observed massive damage to correlate with intense positive flashes. This is attributed in part to the continuing current.

10. "High peak current causes more damage". The damage should correlate most strongly with the energy transferred in the flash, which is given by the action integral $\int I^{2} d t$ over the whole return stroke ([3], Section 18.2). The exact value depends on the current profile throughout the return stroke, but because the current is squared, the peak current should function as a reasonable proxy for the action integral.

11. "High-multiplicity flashes will cause more damage". It could be expected that high multiplicity corresponds to extensive damage, mainly since high multiplicity can imply a continuing current.

The paper is organized as follows. In Section 2, the data collection methodology and final data set are described. In Section 3, two photographed cases are analyzed in more detail. Section 4 describes the data set. In Section 5, the hypotheses made above in Section 1 are tested against the data set. The results are discussed in Section 6, and practical conclusions made in Section 7.

\section{DATA COLLECTION AND METHODOLODY}

A new "flash-based" methodology was tested during the summer of 2007. A number of volunteers were utilized, largely from the storm-chasing section of the Finnish association Ursa. Possible strike locations were identified from the NORDLIS lightning-location information [25]. The nominal location accuracy (the major axis of the $50 \%$ error ellipse) of flashes in the NORDLIS data varied from 200 meters to several kilometers. Even an uncertainty of just 100 $\mathrm{m}$ means that a large area of forest has to be searched; to make searching realistic, only flashes with a nominal location accuracy better than 300 meters were used. Volunteers were sent the information in near real time, and within a few days scoured the locations. Any exceptional findings were noted which could be attributed to intense impulsive events such as lightning flashes. This damage was extensively photographed and documented and then sent to the authors for analysis. This aimed to remove at least some of this observer effect by sampling flashes in an unbiased way. Finland is especially suited for such a study because of several factors. There is a well-established lightning detection network in operation; the country is largely covered in forests, yet there are enough roads to enable 
access to many strike sites; there are very few types of trees (mostly firs and pines in the north, with some birch in the south); and thunderstorms are rare and moderate enough that flash-by-flash correlation is possible.

The use of volunteers obviously raises questions about the validity of the results. None of the volunteers were forestry specialists, but all had sufficient orienteering skills to find the flash locations. The combination of photos and written description gives enough detail that the damage scenario can be reconstructed. It was found that estimating the age of a given damage is particularly difficult, since no data was available on how quickly the marks from a lightning flash will begin to disappear. We therefore made a separate experiment in June 2007 on healthy trees in a volunteer's forest plot (Jaakko and Maija Mäkelä), simulating lightning damage by using a cleaver to cut long gashes or jagged wood-loss-type damage in several firs, pines, and birches. Cuttings from the tree were left lying under the trees. After 3 hours, only the pine tree experienced dramatic changes, the gash filling almost immediately with resin oozing from the tree material and filling the gash without any significant discoloration of the white surface. No sap flowed from the fir or birch trees. After 10 days, there was some discoloration in the fir and birch trees, and none in the pine tree. Small patches of mold began to appear on the fir and birch trees. The cuttings were almost dry, but still identifiable as fresh cuttings. They did not begin to disappear in the grass. Clear signs of discoloration did not appear until about a month later. On the other hand, by the summer of 2008, the scars were in all cases mildewed, and their age could not be determined by an ordinary observer. This experiment showed that flash damage can be reliably observed as long as the damage is fresh, and in principle the flash-based method allows for highly reliable identification of struck trees. In practice, the probability of finding struck trees in this way was found to be extremely small. Altogether, 104 flash sites were scoured; only 4 cases were found which could be definitively identified to be lightning flashes. In addition, there were 10 cases in which some type of damage was observed, but the damage was too "anomalous" to be completely certain that it was lightningcaused. These ten uncertain cases have been analyzed as a separate category. Because of the extremely large workload and low return, we do not expect to repeat this experiment until location accuracies routinely reach 100 meters, decreasing the area to be searched.

During both summers, information was also collected from the public via Internet, which is effectively a case-study method. In 2007, an informal site was set up by Ursa, and information was collected partly by word-of-mouth. In 2008, a web-based questionnaire was posted on the Finnish Meteorological Institute web site. The questionnaire was based on the experience gained during 2007, and asked specifically for information on the parameters which were being tested. Since almost all of the cases were based on eyewitness accounts, the day and often exact time of the strike could be estimated, which enabled the exact flash to be identified with a high degree of certainty. This is assisted by the low flash densities in Finnish thunderstorms.

\section{DESCRIPTION OF TWO PHOTOGRAPHED SPECIAL CASES}

One observer (Niklas Montonen) photographed a flash in Porvoo which hit a European aspen (Populus Tremula) less than 50 meters away. Fig. (1) is a cropped part of the full photograph. Based on location and timing, the flash could be uniquely tied to a $-6 \mathrm{kA}$ flash with multiplicity 1 . As in the case of [5], no damage whatsoever was observed to the tree, nor was any observed when the tree was rechecked in June 2008. As in [5], there had been a considerable amount of rain before the flash (15 $\mathrm{mm}$ in the three hours before the flash). According to the observer, the flash did cause a temporary break in cable TV service to the area.

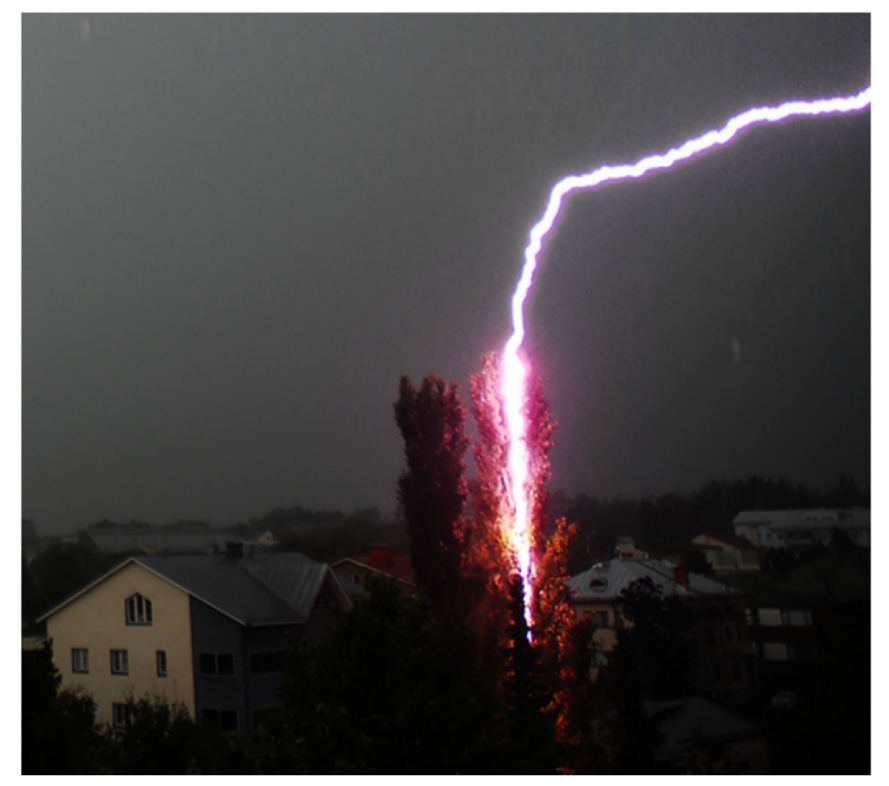

Fig. (1). Picture of lightning flash to nearby tree. No damage to the tree was observed. Picture is cropped from the full image shown in the Appendix. Photograph: Niklas Montonen.

Another observer (Antti Tiihonen) caught a nearby flash in Viikki, Helsinki (Fig. 2). The flash was found to be a -13 kA flash with multiplicity 3 . There had been about $15 \mathrm{~mm}$ of rain in the 24 hours before the flash, and both the ground and the trees would have been saturated with rain. The photograph shows a number of small-scale lightning phenomena which have not often been captured for natural flashes. The flash has at least one fork, which suggests that at least one of the subsequent strokes hit the ground several hundred meters from the others. An unconnected upward leader can be seen rising from the fir tree at the foreground. More weakly, a number of filamentary upward leaders can be seen to be associated with the stroke that is farther away. The return strokes have been overexposed, and it is not possible to see whether there is any fine structure in them. The struck tree in the foreground was found on the following day (Fig. 3). The tree with the upward leader could also be identified on the ground, but sustained no visible damage. The tree in the background that was also struck could not be identified with certainty, indicating that damage to it was small or non-existent. The fine structure seen in the photograph therefore did not appear to cause any visible 
damage; even the return stroke caused only minor bark-loss damage.

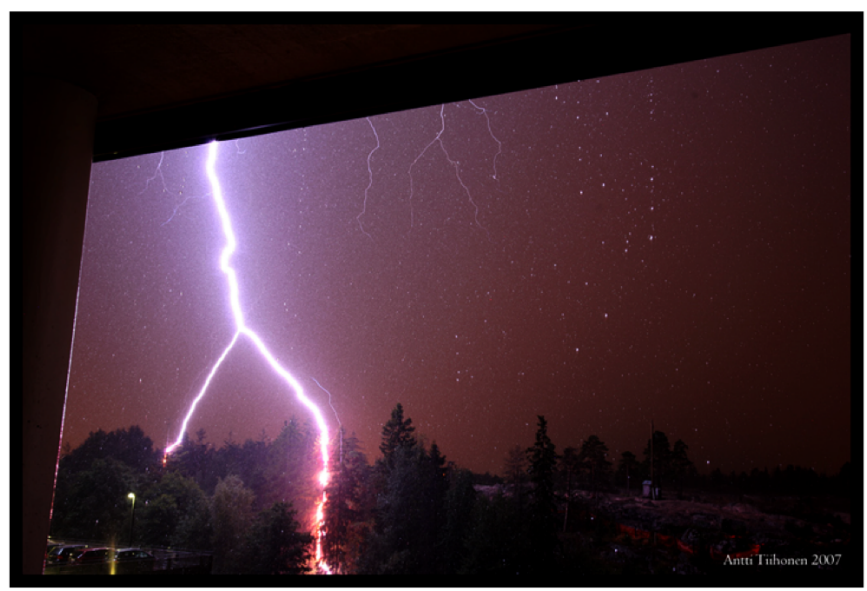

Fig. (2). Viikki case: Picture of three-stroke flash to trees. Phtograph: Antti Tiihonen.

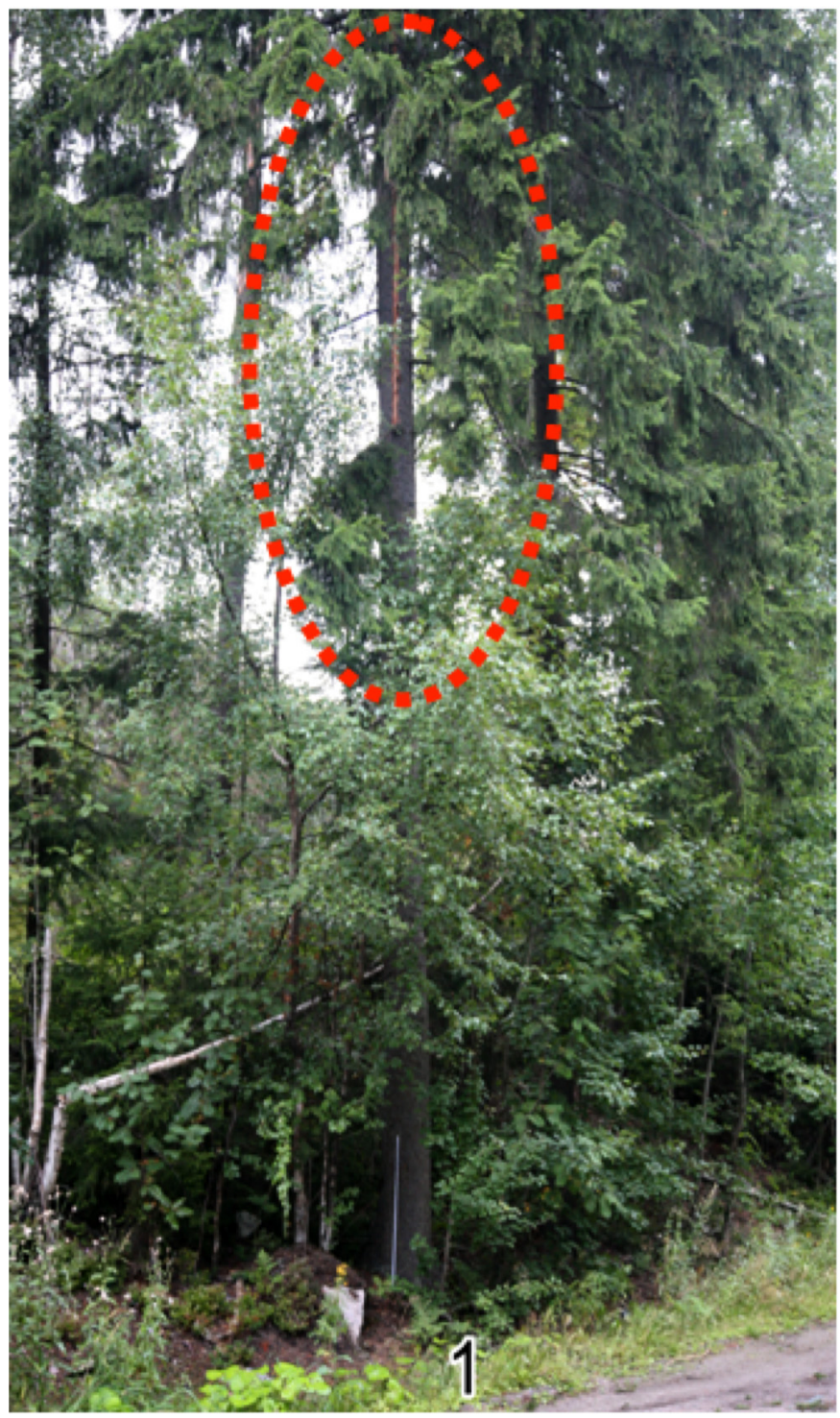

Fig. (3). Viikki case. Classical scar to the main struck tree above 6 meters. No damage to the tree with the attempted leader. Photo: Antti Tiihonen.

\section{RESULTS}

The total number of possible flash sites studied in 2007 was 104. From these sites, only three cases were unambiguous enough to classify as lightning damage. An additional 10 suffered "anomalous" damage. Twelve cases were collected through word-of-mouth or media reports. In 2008 , the Web-based search resulted in 45 reports. In 23 of those cases, there were too many possible flashes in the lightning location data to enable flash identification, but the flash could be identified for 22 cases. The quality-controlled final data set from 2007-2008 thus consists of 37 flashes damaging a single tree. In addition, there were four cases in which damage occurred to multiple trees; these have been left out of the main analysis because of difficulties determining which tree should be used to classify the damage. From 2007, there is also a set of ten "anomalous" cases in which there was impulsive damage to trees close to the flash location given by the lightning detection network. However, the damage does not correspond closely to any of the classical damage mechanisms, consisting mainly of pieces of bark scattered symmetrically around the tree. Although these cases were clearly associated with some type of explosive damage, experienced foresters who were consulted could not be certain that the damage was not caused for example by wind. However, one case in the multiflash series provided direct evidence for such a mechanism: a classical lightning scar was found on a healthy tree that entered the ground through a closeby short stump which was damaged in an "anomalous" way. These cases have therefore been analyzed as a separate category, and any conclusions should be considered tentative.

No exact metric exists to measure the amount of damage to a given tree. However, the division by [10] into bark-loss, wood-loss damage, and explosive damage is very useful. The classification was originally made for evergreen trees. However, we extended the definition to deciduous tree species as well. In a bark-loss case, a strip of bark (usually vertical) is torn off from the tree, but no inner wood is ejected (although vertical cracks may appear in the wood material). In effect, the damage is cause by rapid expansion of the moist material in the cambium, and the current most likely has not penetrated into the inner wood at all.

Fig. (4) shows examples of bark-loss damage in an evergreen and a deciduous tree. Fig. (5) shows a somewhat more unusual bark-loss case in which long strips were torn away. The photo also shows a small furrow in the ground, as well as the vertical cracks described by [10]. In wood-loss cases, some inner wood is ejected as well, but the damage is still restricted to only part of the tree. This implies that current has partly penetrated into the inner wood, although the exact damage-causing mechanism may not be known.Fig. (6) shows a rather typical wood-loss case extending almost the full length of the tree. In explosive cases, the damage is so extensive that the entire tree mass has been blown apart. Fig. (7) shows a fir tree which was essentially demolished. There is some room for subjectivity in classifying individual cases, with the boundary between wood-loss and explosive being particularly fuzzy. However, each of the authors made the classifications independently for each case. Although there were some disagreements classifying between wood-loss and explosive damage, bark- 

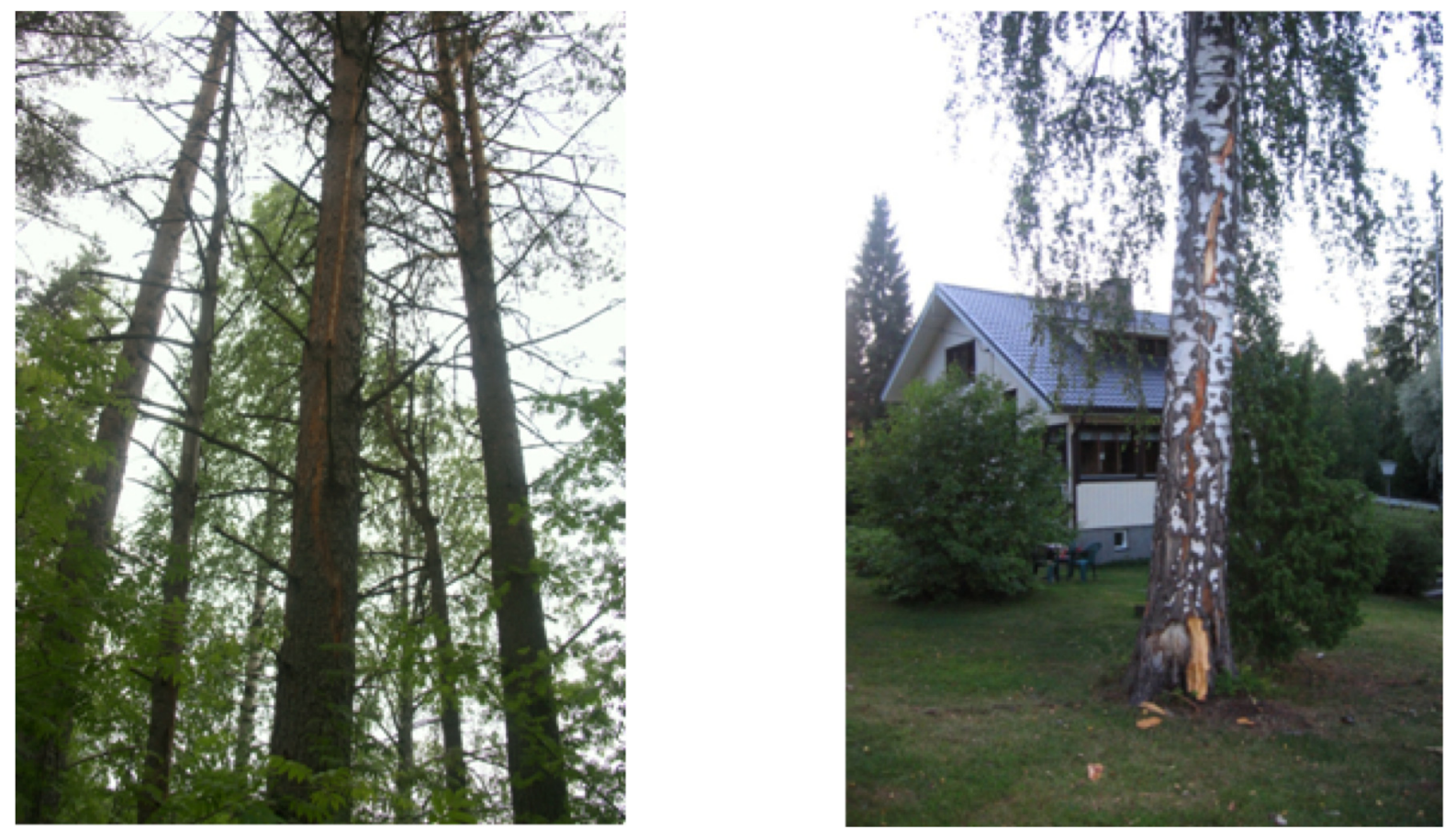

Fig. (4). Bark-loss damage in a fir (left) and birch (right). Photos Esa Tuunanen (left), Jussi Haapalainen (right).

loss cases and wood-loss cases were unambiguously separate. In the 2007 data collected by the "flash-based" method, a number of "anomalous" cases were found (Fig. 8). The mechanism causing the damage was clearly impulsive and the location fits with a flash observed by the lightning detection network, but cannot be identified as lightning

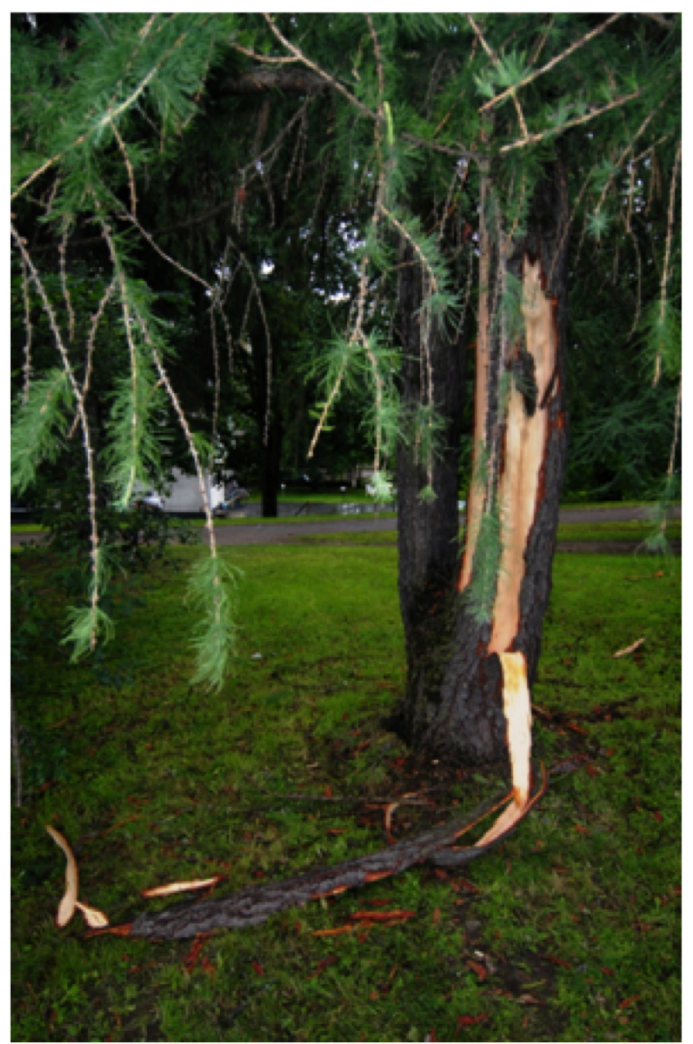

damage with any certainty. Experienced foresters consulted about the damage could neither rule out nor confirm the damage as being lightning-caused. These ten cases have been included in the data set, but analyzed separately.

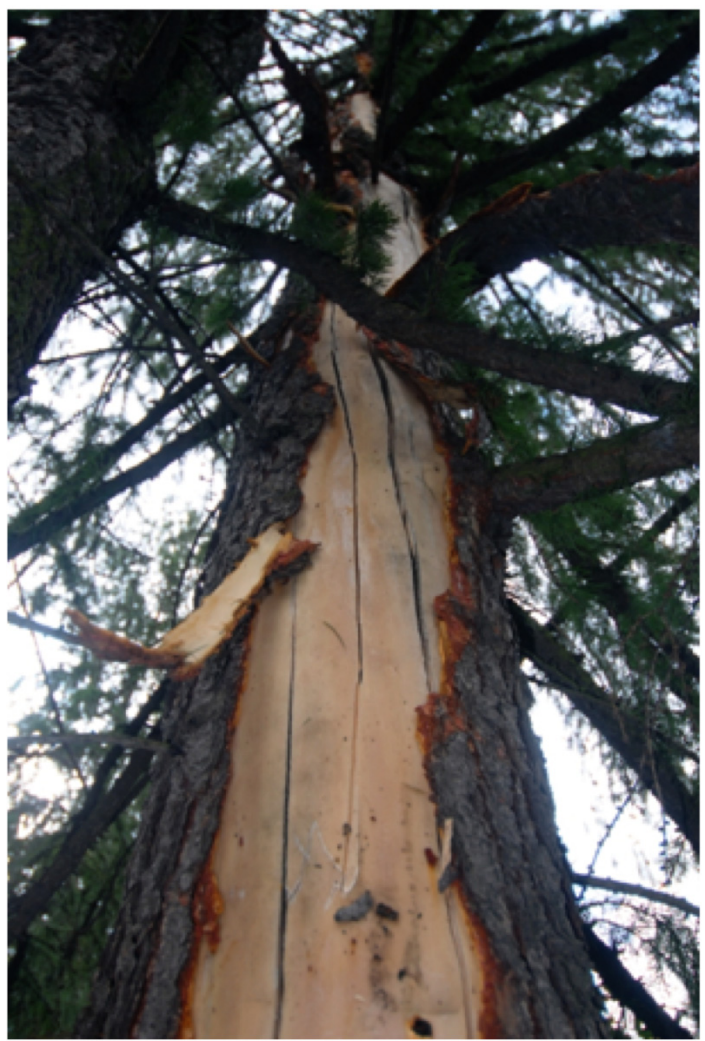

Fig. (5). Unusual bark-loss damage in a larch tree. A weak furrow can be seen in the ground. The tree also exhibits cracks along the grain. Photo: Eero Karvinen. 


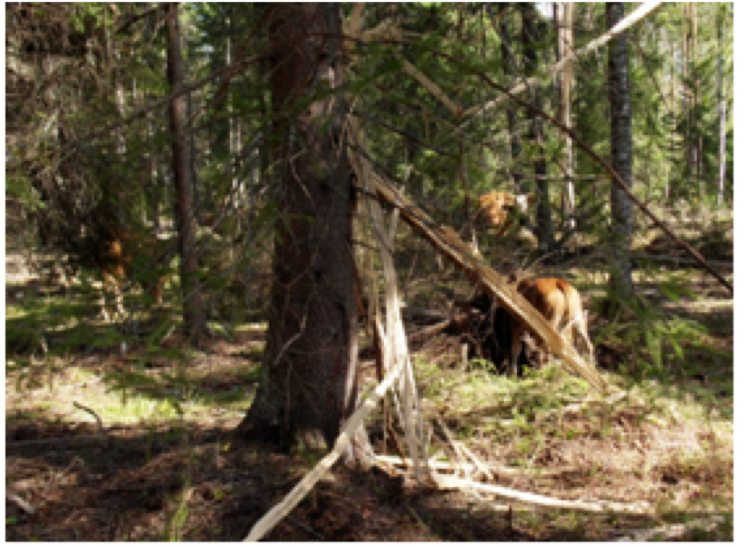

Fig. (6). Wood-loss damage to a fir tree. Photo: Matti Mäkelä.

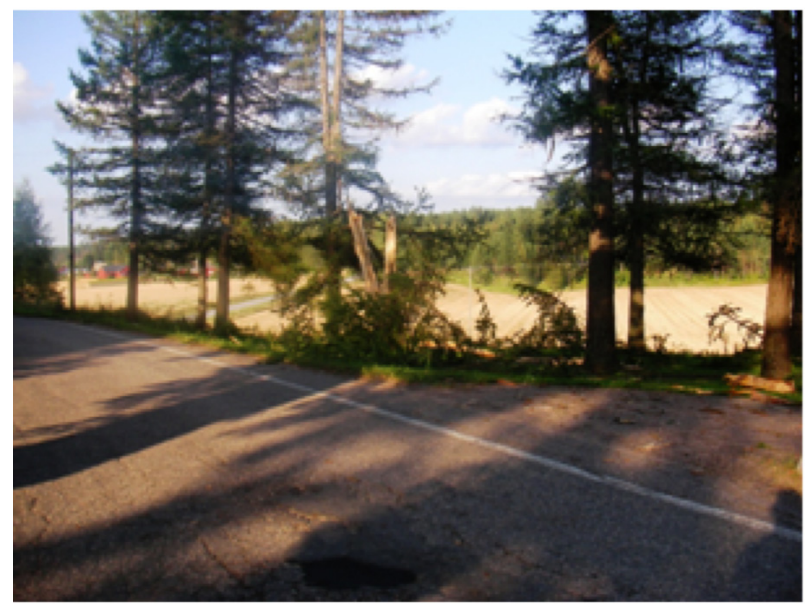

Fig. (7). Explosive damage to a fir tree. Photo: Mats Kommonen.

Table 1 condenses the data set. The final data set used in this analysis has 37 trees; the anomalous and multi-tree cases are handled separately. It is clear that the data collection method has resulted in strong observer bias, as compared to the results of [10]. Wood-loss and explosive cases are far more likely to be reported. This is particularly clear when the two years are compared. In 2007, the data collection was made with a relatively low profile by a small group searching specifically even for minor-damage cases. In 2008, the data were collected almost entirely through the Finnish Meteorological Institute Web site, which has high visibility in Finland. In 2007, wood-loss and explosive losses were $36 \%$ of the data set, while they were $64 \%$ in the 2008 data set.

\section{HYPOTHESIS TESTING}

The hypotheses listed in the Introduction were tested by statistical or indirect methods. A digest of the raw data are shown as Table 2. In all cases, the damage type was correlated with the other parameters. To enable numerical analysis, Nil damage wads given a value of 0 , Bark-loss damage a value of 1 , Wood-loss damage a value of 2 , and Explosive damage a value of 3 . For the parameters with
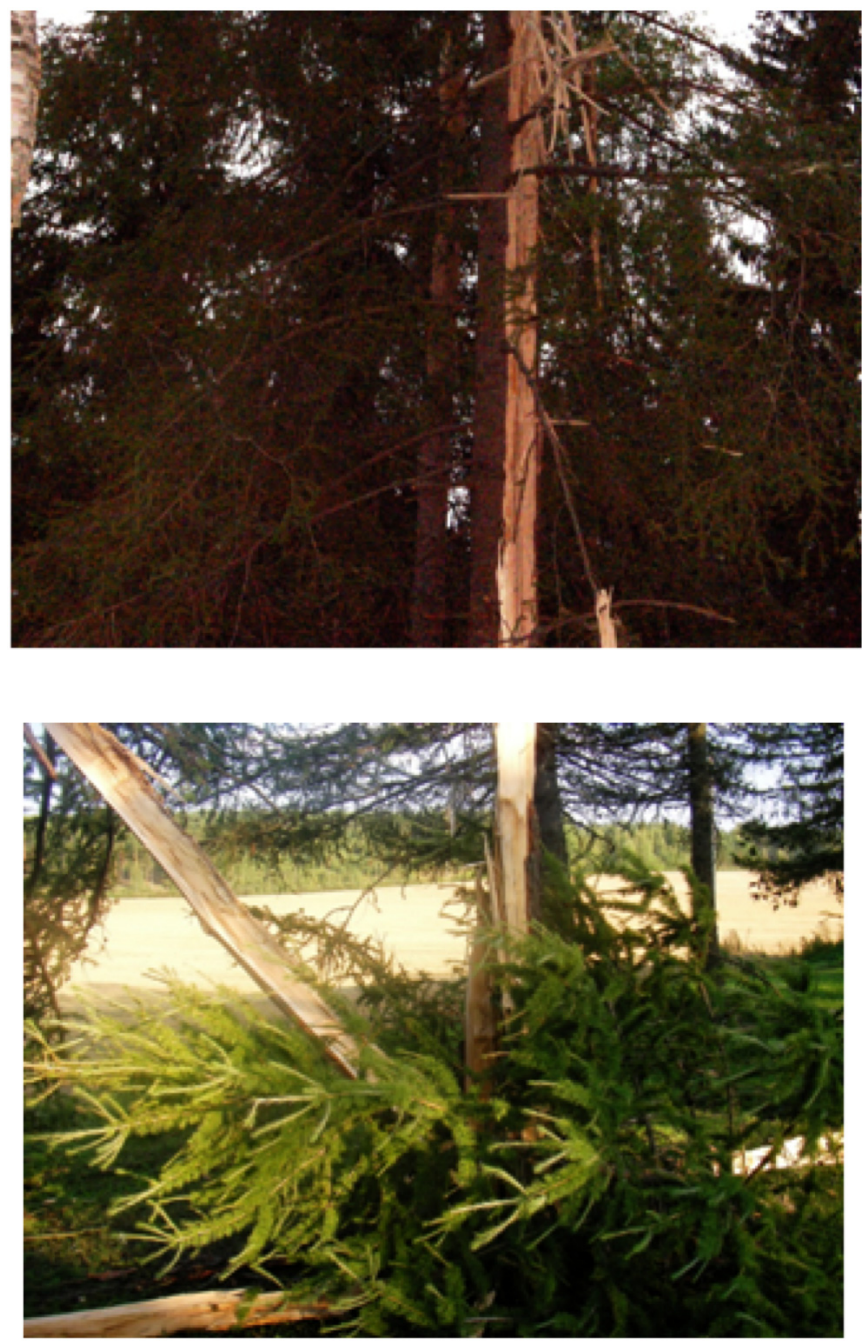

well-defined numerical values, a correlation with the damage parameter could be run; when the parameter had too many uncertainties, the aggregate means for each damage category were calculated. The lightning detection network is optimized to find the location of flashes, and the peak current and multiplicity have more uncertainty [25]. However, for the purposes of this paper the lightning location data has been taken as the ground truth without further quality analysis.

\section{1. "The Highest Trees are Most Likely to be Struck": Inconclusive; Not Necessarily True}

[12] claims that trees which stand well above the neighboring trees are more vulnerable to lightning. This is in general a common-sense assumption, but does not take into consideration the possible interaction between conductivity and height. [15] indeed suggests that this view may however be too simplistic. In more quantitative and theoretically valid terms, the strike probability should be tied to the zone of protection. The zone of protection is used to estimate whether the tree is the structure that "should" have been struck. This evaluation in general had to be done subjectively, based on photographs and verbal descriptions. A simple parameter was 

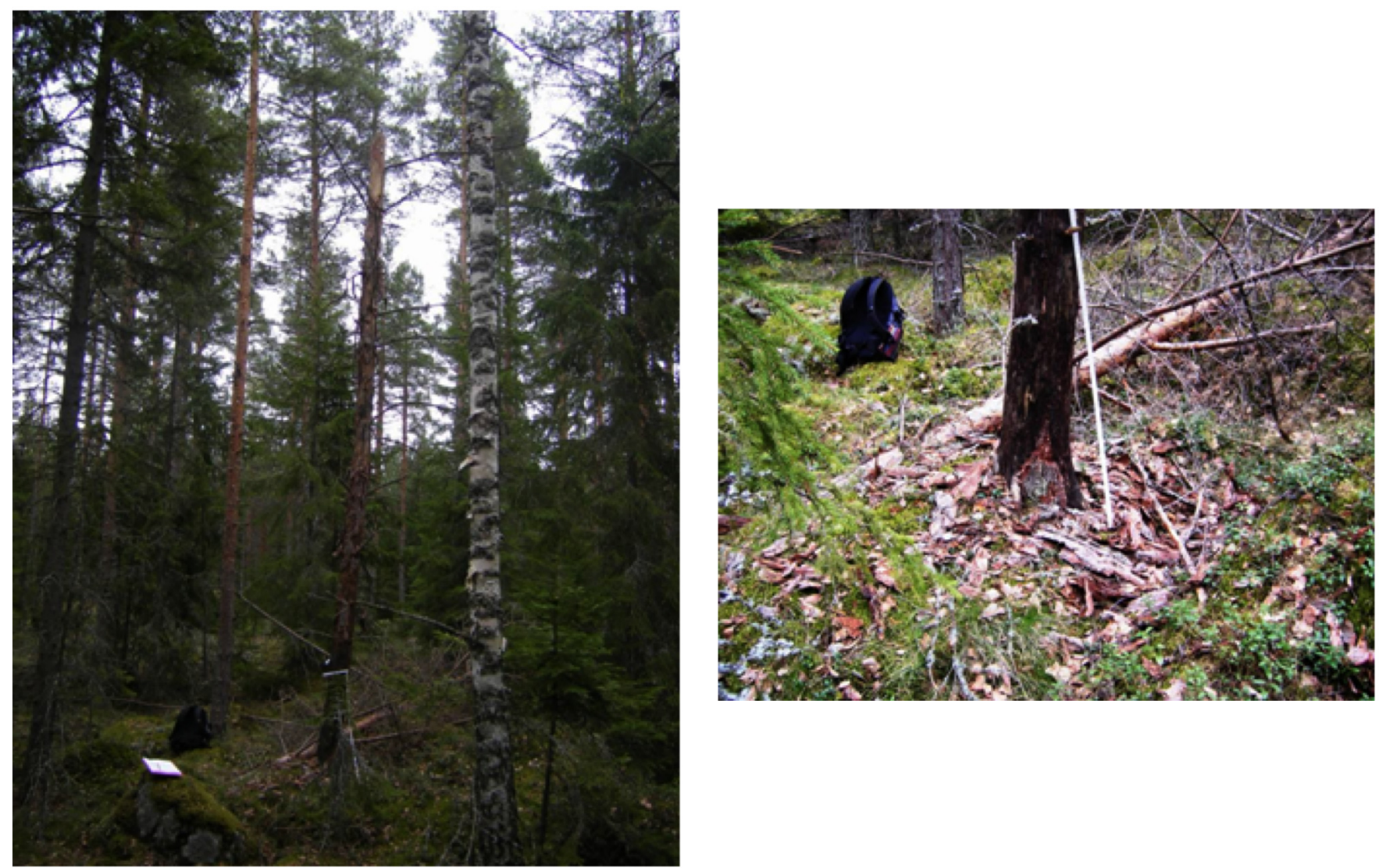

Fig. (8). An "anomalous" case. The bark has been disturbed by a strong impulsive force, but the mechanism cannot be identified as lightning with complete certainty. The lightning-detection network observed a flash at the location. Photo: Jakke Mäkelä.

defined. If the tree was not within the zone of protection of another structure (tree or building), then the tree is the one that "should have been struck" and the parameter was given the value 1 . If the tree was clearly within the zone of protection of another structure, then a value of -1 was given, and if the situation was unclear, the value was set to zero. This determination is unfortunately extremely difficult to make from photographs (or indeed on location). Nevertheless, the average value for the whole data set is 0.1 . This implies that the tree height does not have a correlation with strike probability. However, due to the subjectivity of the analysis, more and better data will need to be collected.

\section{2. "Trees Growing in the Open, or on the Edges of} Forests, are Likely to be Struck": True, But Only Because of Observer Effects

Trees growing in open, either alone or in a small group also in a danger, according to [12]. Since such isolated trees are more likely to be seen by casual observers, this result is definitely affected by observer effects, but there is at present no way of estimating how severe the effect is. Also, [12] suggests that trees growing along avenues or in the border of woods more often struck by lightning. The observer effect is again likely to be severe in this case, with strikes inside dense forests likely to be unobserved. The observer effect is assumed to dominate. However, a subjective estimate was made ( 1 if at the edge, -1 if in deep forest). The average value for the whole set is 0.4 , which means that the found trees were indeed more likely to be near the edge. The "anomalous" cases, on the other hand, were with only one exception found deep within a forest, as were trees in three of the four multi-damage cases. The anomalous cases were specifically searched for rather than being incidentally observed, which suggests that damage that is not visible from the nearest road tends to be ignored. Overall, the data suggest that the hypothesis is entirely due to observer effects.

\section{3. "Trees Growing in Poorly Conducting Ground are More Likely to be Attacked": Inconclusive}

According to [12], trees growing in loam or sandy soils are much more likely to be attacked by lightning than the trees in clay, marl, and calcareous soils. This result has not

Table 1. Damage Statistics by Year

\begin{tabular}{|c|c|c|c|c|c|c|}
\hline Year & Nil & Bark & Wood & Explosive & Anomalous & Multi-Tree \\
\hline \hline 2007 & 1 & 9 & 4 & 1 & 10 & -- \\
\hline 2008 & -- & 8 & 7 & 7 & -- & 4 \\
\hline TOTAL & 1 & 17 & 11 & 8 & 10 & 4 \\
\hline
\end{tabular}


Table 2. Full Statistical Data Set

\begin{tabular}{|c|c|c|c|c|c|c|c|c|c|c|c|c|c|c|c|}
\hline 孚 & 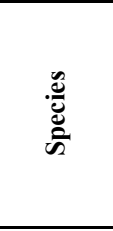 & 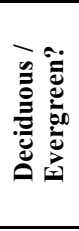 & 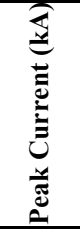 & & 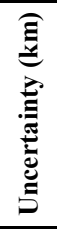 & 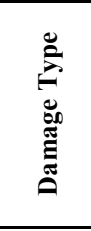 & 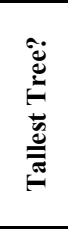 & 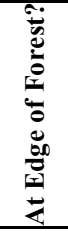 & 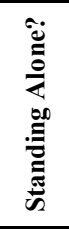 & & 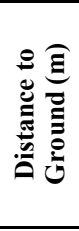 & 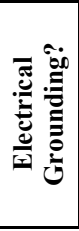 & $\begin{array}{l}\frac{\tilde{m}}{\mathrm{~m}} \\
\underline{\Xi} \\
\stackrel{\Xi}{\tilde{\Xi}}\end{array}$ & 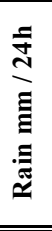 & 苞 \\
\hline 1 & Aspen & $\mathrm{E}$ & -6.0 & 1 & 0.4 & Nil & N/A & Yes & No & Lawn & $>50$ & Yes & 15 & 15 & Disrupted TV cable \\
\hline 2 & Pine & $\mathrm{E}$ & 11.0 & 1 & 0.4 & Bark & Yes & Yes & No & Sandy & $>20$ & Yes & $<1$ & 1 & $\begin{array}{l}\text { Along field telephone } \\
\text { cable }\end{array}$ \\
\hline 3 & Pine & $\mathrm{E}$ & -30.0 & 3 & 0.3 & Bark & No & Yes & No & Sandy & $>50$ & Yes & 10 & 10 & Destroyed electrification \\
\hline 4 & Apple & $\mathrm{D}$ & -7.0 & 1 & 0.3 & Bark & $\mathrm{N} / \mathrm{A}$ & Yes & Yes & Lawn & $>50$ & Yes & 10 & 15 & Disrupted ADSL modem \\
\hline 5 & Willow & $\mathrm{D}$ & -16.0 & 1 & 1.3 & Bark & $\mathrm{N} / \mathrm{A}$ & Yes & No & Sandy & $>3$ & No & 5 & 25 & \\
\hline 6 & Larch & $\mathrm{D}$ & -5.0 & 1 & 0.4 & Bark & Yes & Yes & No & Lawn & $>50$ & No & 5 & 25 & $1 \mathrm{~m}$ shallow furrow \\
\hline 7 & Fir & $\mathrm{E}$ & -13.0 & 3 & 0.4 & Bark & $\mathrm{N} / \mathrm{A}$ & Yes & No & Soil & $>50$ & No & 15 & 15 & \\
\hline 8 & Birch & $\mathrm{D}$ & -29.0 & 2 & 0.4 & Bark & Yes & Yes & N/A & Lawn & $>50$ & Yes & 10 & 15 & $2 \mathrm{~m}$ furrow \\
\hline 9 & Pine & E & -11.0 & 1 & 0.9 & Bark & Yes & Yes & N/A & Lawn & $>50$ & Yes & 15 & 15 & $\begin{array}{l}1 \mathrm{~m} \text { furrow, small stone } \\
\text { raised }\end{array}$ \\
\hline 10 & Pine & $\mathrm{E}$ & 46.0 & 1 & 0.2 & Bark & Yes & Yes & No & Sandy? & $>50$ & Yes & 1 & 1 & Destroyed buildings \\
\hline 11 & Birch & $\mathrm{D}$ & -3.5 & 1 & 3.0 & Bark & No & No & Yes & Soil & $>50$ & No & 5 & 5 & Nearby stump in flames \\
\hline 12 & Pine & $\mathrm{E}$ & -10.1 & 1 & 0.3 & Bark & Yes & No & No & Rocky & $>3$ & No & 1 & 1 & Wildfire (about 1 ha) \\
\hline 13 & Pine & $\mathrm{E}$ & 5.5 & 1 & 0.6 & Bark & No & Yes & No & Rocky & $>50$ & Yes & 1 & 1 & $\begin{array}{c}10 \mathrm{~m} \text { furrow; buildings } \\
\text { damaged }\end{array}$ \\
\hline 14 & Birch & $\mathrm{D}$ & 37.8 & 1 & 0.3 & Bark & No & Yes & No & Soil & $<3$ & No & 1 & 10 & $2 \mathrm{~m}$ furrow \\
\hline 15 & Pine (d) & $\mathrm{E}$ & 10.2 & 1 & 1.4 & Bark & No & Yes & Yes & $?$ & $>50$ & No & 10 & 10 & \\
\hline 16 & Pine & $\mathrm{E}$ & -17.6 & 1 & 0.5 & Bark & Yes & Yes & No & Rocky & $>50$ & No & 10 & 15 & Electricity went dead \\
\hline 17 & Birch & $\mathrm{D}$ & -7.2 & 1 & 0.5 & Bark & No & Yes & No & Wet & $>3$ & No & 1 & 1 & \\
\hline 18 & Larch & $\mathrm{E}$ & -9.2 & 3 & 0.5 & Bark & Yes & Yes & Yes & Wet clay & $>3$ & No & 25 & 25 & \\
\hline 19 & Fir & $\mathrm{E}$ & -13.0 & 1 & 1.7 & Wood & $\mathrm{N} / \mathrm{A}$ & No & No & Soil & $>50$ & No & 5 & 25 & \\
\hline 20 & Fir & $\mathrm{E}$ & -19.0 & 3 & 0.3 & Wood & $\mathrm{N} / \mathrm{A}$ & Yes & No & 0.0 & $>50$ & No & 15 & 15 & \\
\hline 21 & Fir & $\mathrm{E}$ & -20.0 & 6 & 0.3 & Wood & N/A & No & No & Swampy & $>50$ & No & 1 & 1 & Blackening, hole \\
\hline 22 & Pine & $\mathrm{E}$ & -27.0 & 8 & 0.3 & Wood & $\mathrm{N} / \mathrm{A}$ & "Yes & No & Lawn & $>50$ & No & $<1$ & 1 & \\
\hline 23 & Birch & $\mathrm{D}$ & -25.0 & 2 & 0.4 & Wood & N/A & "Yes & No & Sand & $<3$ & Yes & 10 & 10 & \\
\hline 24 & Birch & $\mathrm{D}$ & 18.7 & 1 & 1.1 & Wood & Yes & "Yes & 0.0 & Swamp & $>50$ & No & 1 & 5 & \\
\hline 25 & Fir & $\mathrm{E}$ & -17.0 & 1 & 0.5 & Wood & N/A & No & No & Soil & $>50$ & No & 1 & 5 & \\
\hline 26 & Birch & $\mathrm{D}$ & -14.3 & 1 & 0.4 & Wood & Yes & Yes & No & Sand & $>20$ & Yes & 1 & 1 & Electrification destroyed \\
\hline 27 & Pine & $\mathrm{E}$ & -21.0 & 1 & 0.4 & Wood & N/A & No & No & Swampy & $>3$ & No & 5 & 20 & \\
\hline 28 & Birch & $\mathrm{D}$ & -7.7 & 1 & 0.4 & Wood & N/A & Yes & Yes & $?$ & $>50$ & Yes & 10 & 10 & $\begin{array}{c}\text { Nearby traffic lights went } \\
\text { off }\end{array}$ \\
\hline 29 & Larch & $\mathrm{E}$ & -30.9 & 4 & 0.2 & Wood & Yes & Yes & $\mathrm{N} / \mathrm{A}$ & Soil & $>20$ & No & 5 & 5 & \\
\hline 30 & Fir & $\mathrm{E}$ & -12.0 & 2 & 0.4 & Expl & $\mathrm{N} / \mathrm{A}$ & Yes & N/A & Sandy & $>50$ & Yes & 1 & 1 & \\
\hline 31 & Pole & $\mathrm{N} / \mathrm{A}$ & 59.1 & 2 & 0.5 & Expl & $\mathrm{N} / \mathrm{A}$ & No & Yes & Swampy & $>50$ & No & 1 & 5 & $20 \mathrm{~m}$ long furrows \\
\hline 32 & Pine (d) & $\mathrm{E}$ & 7.3 & 1 & 0.4 & Expl & $\mathrm{N} / \mathrm{A}$ & $\mathrm{N} / \mathrm{A}$ & Yes & Rocky & $>3$ & Yes & 1 & 1 & Electrification destroyed \\
\hline 33 & Fir & $\mathrm{E}$ & -38.5 & 2 & 0.2 & Expl & No & Yes & N/A & Sand & $>50$ & Yes & 5 & 5 & Jumped to a streetlight \\
\hline 34 & Fir & $\mathrm{E}$ & -62.8 & 1 & 0.3 & Expl & $\mathrm{N} / \mathrm{A}$ & No & N/A & Soil & $>50$ & No & 1 & 1 & \\
\hline 35 & Birch & $\mathrm{D}$ & -16.3 & 1 & 0.3 & Expl & No & Yes & Yes & Soil? & $>20$ & No & 1 & 1 & \\
\hline 36 & Birch & $\mathrm{D}$ & 14.5 & 2 & 0.3 & Expl & Yes & Yes & N/A & Soil & $>50$ & No & 1 & 1 & \\
\hline 37 & Birch & $\mathrm{D}$ & 65.7 & 1 & 0.9 & Expl & $\mathrm{N} / \mathrm{A}$ & Yes & N/A & Soil & $>20$ & Yes & 1 & 5 & Some broken fuses \\
\hline
\end{tabular}


been verified in later studies. The type of ground was evaluated for conductivity. Ground conductivity is a problematic parameter to measure, since the variations can be over many orders of magnitude. The conductivity is known to be a function primarily of the water content and water type in the soil, according to [21]. However, [21] estimates typical resistivities of about $25-70 \Omega \mathrm{m}$ for clay, $50-250 \Omega \mathrm{m}$ for cultivated soil, and 1000-3000 $\Omega \mathrm{m}$ for sand, and much higher for rock. An approximately logarithmic scale was adopted to estimate the conductivity from the photographs. Dry, rocky ground was given value 0 ; sandy ground (including yards) a value of 1; soil or clay a value of 2 ; and very swampy ground a value of 3 . Estimated this way, damage and conductivity were found to have a statistically significant correlation of 0.33 . The ground type may therefore have an effect, but in the opposite direction than [12] proposes: high-conductivity ground is more likely to cause high damage. However, since no actual measurements of the conductivity could be made and the water content is in any case the dominating parameter, the results are not conclusive.

\section{4. "Ground Moisture Affects Tree Damage": True, with Moistness Protecting the Tree}

[12] suggests that trees growing in moist soil are better conductors than other trees. This is tied to precipitation. The amount of rain in the previous 24 hours was estimated from weather radar data; the nominal accuracy is $5 \mathrm{~mm} / 24 \mathrm{hr}$, but in many cases the rainfall varies dramatically over very small distances. A statistically significant correlation of -0.45 was found with the 3-hour rainfall amount (for the 24-hour rainfall, the correlation is an essentially identical -0.42 ). The mean values are shown in the table below. Clearly, rainfall has the effect of "protecting" the tree from massive damage. This effect is known to be true for forest fires, but has not been demonstrated for damage in general. The "anomalous" cases had average values of 5.3 and $8.5 \mathrm{~mm}$. For multi-tree cases, the values were 0.7 and $4.0 \mathrm{~mm}$, which implies a dry ground. The statistics show that the effect of rainfall is on average to protect the tree against damage. It is not possible from this data set to determine whether rainfall affects the strike probability or simply the damage probability

Table 3. Damage Type Versus Rainfall

\begin{tabular}{|c|c|c|}
\hline Damage Type & 3-Hour Rainfall (mm) & 24-Hour Rainfall (mm) \\
\hline \hline Nil & 15.0 & 15.0 \\
\hline Bark-loss & 7.4 & 11.2 \\
\hline Wood-loss & 5.0 & 8.9 \\
\hline Explosive & 1.5 & 2.5 \\
\hline Average & $\mathbf{5 . 6}$ & $\mathbf{8 . 7}$ \\
\hline
\end{tabular}

\section{5. "Certain Tree Types are More Vulnerable than Others": Inconclusive}

At the macrophysical level, no correlation was found between tree species and extent of damage. However, the data set is still relatively small and dependent on multiple parameters.

\section{6. "Poor-Quality Trees are More Likely to be Destroyed": True}

Sound trees in general are less likely to be seriously damaged than old or otherwise damaged trees ([12]). This tends to be supported by case studies such as that of [8]. The mechanism proposed by [2] is that there are voids and ruptures within the core wood in such trees, which means that flashover may be guided into the tree rather than to the outside. The current would then flow through the tree, and the vaporizing of the steam would produce forces strong enough to explode the whole tree. A subjective assessment was made based on photographs and descriptions. A value of -1 was given for young healthy tree; +1 for clearly predamaged or decaying trees; and 0 when no clear determination could be made. Here, some statistically valid results were in fact seen, with a 0.34 correlation. In particular, all of the explosive cases involved trees that were either clearly diseased or could not be identified, while such trees constituted less than one third of both bark-loss and wood-loss cases. Of the "anomalous" cases, $60 \%$ were dead or dying trees. Clearly, the anecdotal evidence cited in earlier literature is valid: old and damaged trees run the highest risk of being explosively damaged.

\section{7. "Closeby Grounding can Protect a Tree": Inconclusive}

An additional parameter that was hypothesized to affect tree damage was the presence or proximity of a useful electrical ground. This ground can be either a body of exposed water (creek, large puddle, lake, sea) or an electric wire or underground cable. The distance to the nearest body of water was estimated. The presence of a body of water is divided into four categories. 3: Close enough for direct flashover from tree to water (less than $3 \mathrm{~m}$ ); $2: 3-20 \mathrm{~m} \mathrm{1:20-}$ $50 \mathrm{~m} \mathrm{0}:>50 \mathrm{~m}$. The flash was assumed to have hit an electric wire if damage was reported or it was otherwise clear that the flash had traveled along a ground wire (category 1), otherwise zero. No dependence on category was observed. The "anomalous" cases differed significantly from the others. The average value was 1.7 , and the majority of the cases were very close to a body of water. Overall, the presence of a good electric ground does not appear to affect damage.

\section{8. "Positive Currents Cause More Damage": Indirectly Supported}

Because the data sets are small, it is not possible to evaluate the effect of polarity statistically. However, it is noteworthy that 10 of the 36 flashes were positive (28\%), which is higher than the $16 \%$ average for Finland ([25]). Thus, positive flashes do appear to be likely to cause observable damage.

\section{9. "High Peak Current Corresponds with Large Damage": Supported}

The absolute value of the peak current in the first return stroke was found to have the strongest correlation with damage, with a correlation of 0.45 . Thus, a flash with a high peak current is more likely to cause significant damage. Specifically, the explosive cases are associated with large 
Table 4. Damage Type Versus Flash Parameters

\begin{tabular}{|c|c|c|c|c|}
\hline Positive Flashes & Positive Flashes (All Flashes) & Mean Current & Median Current & Range \\
\hline \hline Bark-loss & $5(17)$ & $+22 \mathrm{kA}$ & $+11 \mathrm{kA}$ & $10-46 \mathrm{kA}$ \\
\hline Wood-loss & $1(11)$ & $+19 \mathrm{kA}$ & $(+19 \mathrm{kA})$ & $(19 \mathrm{kA})$ \\
\hline Explosive & $4(8)$ & $+37 \mathrm{kA}$ & $+37 \mathrm{kA}$ & $7-66 \mathrm{kA}$ \\
\hline Average & $\mathbf{1 0}(\mathbf{3 6})$ & $+\mathbf{2 8} \mathbf{k A}$ & $\mathbf{- 1 7} \mathbf{k A}$ & $\mathbf{7 - 6 6 ~ k A}$ \\
\hline
\end{tabular}

\begin{tabular}{|c|c|c|c|c|c|}
\hline Negative Flashes & Negative Flashes & Mean Current & Median Current & Range & Mean Multiplicity \\
\hline \hline Bark-loss & $12(17)$ & $-13 \mathrm{kA}$ & $-11 \mathrm{kA}$ & $4-30 \mathrm{kA}$ & 1.4 \\
\hline Wood-loss & $10(11)$ & $-20 \mathrm{kA}$ & $-20 \mathrm{kA}$ & $12-63$ & 2.6 \\
\hline Explosive & $4(8)$ & $-32 \mathrm{kA}$ & $-27 \mathrm{kA}$ & $\mathbf{4 - 6 3} \mathbf{k A}$ & $\mathbf{1 . 5}$ \\
\hline Average & $\mathbf{2 6}(\mathbf{3 6})$ & $\mathbf{- 2 0 ~ k A}$ & $\mathbf{- 1 7} \mathbf{k A}$ & \\
\hline
\end{tabular}

peak currents, both negative and positive. Explosive damage was associated in $50 \%$ of the cases with intense positive flashes (average $+37 \mathrm{kA}$ ), and when caused by negative flashes, the average peak current was $-32 \mathrm{kA}$. These are larger than the Finnish averages calculated by [25] (-16 kA for negatives, $+23 \mathrm{kA}$ for positives). The peak currents for bark-loss and wood-loss cases are however not significantly higher than these average values. The multi-tree cases varied from $-7 \mathrm{kA}$ to $-35 \mathrm{kA}$, with multiplicities 1 to 6 . The anomalous cases had very large variations (from -8 to $98 \mathrm{kA}$ ) so that the mean value is not a good metric.

\subsection{0. "High Multiplicity Corresponds with Damage": Not Supported}

The data above do not show a correlation between damage and multiplicity as determined from the lightning location network. No statistical correlation with flash multiplicity was found, but it is an open question how accurate the network is in measuring multiplicity. The woodloss cases have an average multiplicity of 2.6 while the average for the overall set is 1.5, which is typical for Finnish lightning ([25]). However, the average for the wood-loss case is dominated by two flashes with multiplicities 6 and 8 . If these outliers are removed, the average multiplicity is 1.5 for all damage categories. Flash multiplicity therefore does not appear to affect the damage.

\subsection{1. "Continuing Currents Cause More Damage": Inconclusive, Due to Measurement Limitations}

Continuing currents can only be measured indirectly. As observed by [26], high multiplicity means a higher probability of a continuing current; large positive currents also imply continuous currents ([8]). The statistical results above do show an increased probability of positive flashes, but no unusually large multiplicities. This data set is therefore insufficient to make a determination on continuing currents.

\section{DISCUSSION}

Our paper presented the first large-scale study of lightning-caused tree damage where the individual flash and other meteorological parameters are known. As a practical conclusion, the project shows that "professional-amateur" collaborations can be useful in lightning research. The data set of this paper could clearly not have been collected without the large volunteer effort and Internet-based collection methods. The data set contained 37 trees. The study of [10] had a far larger set of trees, but limited to one tree type (Douglas firs) and had no information on flash time or parameters. In our study, the effects of the lightning flash parameters, tree characteristics, meteorological conditions, and nearby small-scale terrain effects could be evaluated for individual flashes. Because the damage mechanisms are so different for the various tree types, any "damage value" must be evaluated partly subjectively. For evergreens, the distinction between bark loss and wood loss made by [10] is a useful guide. We extended the definition to include deciduous trees as well.

Various parameters were estimated and correlated with the observed damage. One finding which seems inconsistent with "common knowledge" is the effect of tree height. Based on an analysis of photographs, it was found that relatively often, the struck tree was within the protective zone of another structure (higher tree or building). It is clear that this finding is problematic due to the subjective nature of the evaluation (base on photographs) and the lack of exact measurements of the tree heights. However, we are not aware of any earlier studies on the strike probabilities of natural lightning to natural objects such as trees. Thus, even though this result may be invalidated as more data are collected, it should at least be considered as a rationale to analyze the effect of resistance and height further. The observed trees tended to be near the edges of forests or standing alone, as suggested by [12]. On the other hand, there is little reason to assume that this is anything but an observer effect.

Ground conductivity was estimated from photographs. A weak but statistically significant correlation was found, with high conductivity implying increased damage. However, the ground conductivity is dominated by the water content of the soil ([21]), which in turn can be estimated from rainfall data. Three-hour rainfall and damage were found to have a negative correlation of $r=-0.45$, which means that a moist 
ground and tree surface tend to protect the tree. A wet ground and tree surface appear to provide a pathway which is more preferable for the current than passing through the wood material.

No systematic differences were found between tree types. The long-term biological damage e.g. through insect infestation ([18]) may vary depending on the tree type, but at the macrophysical level no differences were seen. Deciduous trees appear just as likely to experience wood-loss damage as evergreens. A statistically significant 0.34 correlation was found between the (subjective) decay level of a tree and the damage to the tree. This is consistent with earlier literature, by which severe damage would be associated with old and possibly damaged trees. In our data set, tree quality does not appear to determine whether minor damage (bark-loss or wood-loss) occurs. However, explosive damage appears to require an old or pre-damaged tree, presumably because the inner wood is then moist and well-conducting, leading to inwood breakdown as suggested by [19].

An attempt was made to estimate whether the proximity of a good electrical ground affects the results. The rationale was that a good electrical ground (e.g. river or other body of water) would provide a preferred path for the current. Due in part to difficulties in interpreting the photographs, no conclusions can be drawn at present.

The flash characteristics are the most unambiguous parameter for statistical studies. Continuing currents are expected to be the most reliable predictor of damage, but could not be directly measured. Indirectly, large-amplitude positive flashes or high-multiplicity negative flashes would correlate with continuing currents. The results are inconclusive. There were more positive flashes than would be expected in a random distribution, and in particular the explosive cases were associated with intense positives. On the other hand, the multiplicities were not high. Peak currents are expected to correlate with the action integral, which in turn is expected to correlate with the damage. Explosive damage was indeed associated with significantly higher than average peak currents, but the currents for the weaker damage types were average for Finland. Multiplicities were also statistically typical. Overall, tree damage does correlate with flash parameters that can be measured remotely, but the correlation is not strong enough to predict the effect of any flash with any reliability. The lack of correlation between peak intensity and damage is similar to the effect observed by [23], in which forest fire ignition probability was not dependent on lightning peak current. [23] further observed a decrease in ignition probability as a function of multiplicity. In our results, the multiplicity appears to have little effect. Although the mechanisms causing forest fires are not necessarily related to other macrophysical damage, these results imply that remote detection does not predict damage very accurately. This is of practical significance in applications in which potential damage is remotely estimated from lightning location data.

The results suggest three particularly important avenues for future research. Data collection will be continued at least during the summer of 2009, which may provide some answers. In the Introduction of this paper, it was suggested that trees could provide a unique record of the lightning attachment, and hence the fine details could be used to make inferences about the attachment process. Although the trees in paper analyzed for several parameters including multiplicity versus number of scars, the number of events so far is too small to draw any real conclusions.

A second question is whether attachment to trees requires modifications to standard models of lightning attachment. It is possible that normally used lightning protection models based on electrogeometric methods (used specifically for the case of trees by [27]) can be problematic when the conditions are non-ideal. The struck trees were often not the highest; in some cases there were high grounded buildings nearby which should in principle have been more likely to get struck. The photographic method was however not suitable for very accurate measurements of the quantitative heights and distances. Overall, the models of lightning attachment to a tree would benefit from an analysis in which the resistance was considered variable. One of the photographed cases (Fig. 2) particularly important for understanding the attachment effects. It is seen that the highest tree produced an upward leader that was unattached; the actual flash followed a nearby lower tree, with a tortuous path. The initiation of an upward leader requires both a sharp point to raise the electric field above the breakdown voltage, and a conducting path to allow the current to pass through. Although a higher tree should have a larger electric field at the tip, the lower resistance of a decaying stump can cause it to be the favored path. A related effect may be that observed in controlled environments by [28], in which artificial lightning currents tend to avoid striking high trees when a better grounding is available lower down. We suggest that to determine the path of the current, several factors need to be considered separately: the field intensification due to a sharp peak, the conductivity of the tree, the location of the best electrical ground, and the best path down to the electrical ground.

A third question is to estimate whether standard lightning-protection schemes need modification when trees are part of the area to be protected. Five of the reported cases caused extensive damage to nearby electrical equipment through the ground current, which implies that even correctly grounded lightning protection would not necessarily have protected the buildings. Damage from side flashes was not directly observed, although some of the connections to the electrical wires may have been due to a side flash. Such side flash damage has been reported e.g. by [29]. However, the protection level of the buildings was not specifically analyzed in this project.

\section{CONCLUSIONS}

Lightning attachment to trees was studied based on 37 trees that were struck in Finland in 2007 and 2008. Data was collected by volunteers from the Ursa amateur storm-chaser section in summer 2007, and by a Web-based tool operated by the Finnish Meteorological Institute in 2008. In each of the cases, the damage to the tree was correlated with multiple parameters. Strike probabilities cannot be directly calculated because of the methodology. However, when the locations around the trees were scanned from photographs, it was found that the struck trees are not systematically the highest trees. This suggests that for natural attachment to trees (which have variable conductivity), both the height and 
conductivity affect the strike probability. The role of conductivity was estimated by identifying the ground type, and in particular by measuring the rainfall before the flash. The dry-ground conductivity was found to have little effect on the damage; however, rain saturation was found to be a key parameter in predicting the amount of damage, with almost all wood-loss and explosive cases occurring when the ground and tree were still dry. Generally, prediction of tree damage cannot be based on a single parameter. From a lightning-protection viewpoint, several of the cases caused considerable damage to building electrification through the passage of the ground current, which implies that trees can cause problems for the lightning protection especially of low houses.

\section{ACKNOWLEDGEMENTS}

We thank the Finnish Meteorological Institute for allowing the real-time lightning-location data service to be used for this project. We sincerely thank Ursa ry for providing volunteers and logistical support especially in 2007. The following people participated in the flash-based searches and are thanked for their patience: Tom Ahola, Jukka Hölttä, Henri Kankkio, Tomi Karvonen, Jaakko Mäkelä, Matti Mäkelä, Teemu Mäntynen, Petri NurkkaTuorila, Tero Pajala, Jarmo Rajamäki, Panu Räty, Petri Sirkkala, and Esa Tuunanen. Photographs and reports of individual cases were provided in 2007 by Antti Aarva, Pyry Ekholm, Jussi Haapalainen, Ilkka Juga, Mats Kommonen, Leevi Korpela, Kim Lund, Kari Ristola, and Markku Vahter, and by multiple observers in 2008. We especially thank Antti Tiihonen and Niklas Montonen for their unique lightning photographs. We thank Jaakko and Maija Mäkelä for allowing trees on their property to be sacrificed for reference purposes.

\section{REFERENCES}

[1] Golde RH. Lightning Protection. London: Edward Arnold 1973.

[2] Taylor AR. Lightning and Trees. In: Golde RH, Ed. Lightning, Lightning Prot 1977; vol. 2.

[3] Rakov VA, Uman MA. Lightning: Physics and Effects. Cambridge: University Press 2003.

[4] Uman MA. The Art and Science of Lightning Protection. Cambridge: University Press 2008.

[5] Orville RE. Photograph of a close lightning flash. Science 1968; 162: 666-7.

[6] Stevens AF. Lightning explodes trees and digs trenches. Mon Weather Rev 1921; 49(4): 241-2.

[7] Norbury FP. Unique destruction of a tulip tree by lightning. Mon Weather Rev 1927; 55(6): 268.
[8] Heidler F, Diendorfer G, Zischank W. Examples of trees severely destructed by lightning. International Conference on Lightning and Static Electricity, Seattle USA 2005.

[9] McAdie A. An unusual lightning flash. Mon Weather Rev 1929; 57(5): 197-9.

[10] Taylor AR. Lightning damage to forest trees in Montana. Weatherwise 1964; 61-5.

[11] Which trees attract lightning? Mon Weather Rev 1898; 26(6): 2578.

[12] Covert RA. Why an oak is often struck by lightning: a method of protection of trees against lightning. Mon Weather Rev 1924; 4923.

[13] Magnusson WE, Lima AP, Lima OD. Group lightning mortality of trees in a Neotropical forest. J Trop Ecol 1996; 12: 899-903.

[14] Darveniza M, Zhou Y. Lightning-initiated fires: Energy absorbed by fibrous materials from impulse current arcs. J Geophys Res 1994; 99(D5):10,663-10,70.

[15] Taylor AR. Lightning -- agent of change in forest ecosystems. J Forest 1971; 69(8): 476-80.

[16] Franklin JF, Shugart HH, Harmon ME. Tree death as an ecological process. BioScience 1987; 37(8): 550-6

[17] Anderson NH, Anderson DB. Ips bark beetle attacks and brood development on a lightning-struck pine in relation to its physiological decline. Fla Entomol 1968; 51(1): 23-30.

[18] Rykiel JR, Coulson RN, Sharpe PJH, Allen TFH, Flamm RO. Disturbance propagation by bark beetles as an episodic landscape phenomenon. Landscape Ecol 1988; 1(3): 129-39.

[19] Darveniza M. Electrical Properties of Wood and Line Design. St Lucia, Queensland: University of Queensland Press 1980.

[20] Darveniza M, Limbourn GJ, Prentice SA. Line design and electrical properties of wood. IEEE Trans Power Apparatus Syst 1967; PAS-86(11): 1344-56.

[21] Saraoja EK. Lightning earths. In: Golde RH, Ed. Lightning, Lightning Protection. New York: Academic Press 1977; vol. 2.

[22] Simpson W, TenWolde A. Physical properties and moisture relations of wood. Wood handbook -- Wood as an Engineering Material. Madison, WI: US Department of Agriculture, Forest Service, Forest Products Laboratory 1999.

[23] Larjavaara M, Pennanen J, Tuomi TJ. Lightning that ignites forest fires in Finland. Agric For Meteorol 2005; 132(3): 171-80.

[24] Shindo T, Uman MA. Continuing current in negative cloud-toground lightning. J Geophys Res 1989; 94: 5189-98.

[25] Tuomi TJ, Mäkelä A. Lightning observations in Finland 2007. Reports of the Finnish Meteorological Institute, Helsinki 2007.

[26] Rakov VA, Uman MA. Long continuing current in negative lightning ground flashes. J Geophys Res 1990; 95(D5): 5455-70.

[27] Mousa AM, Srivastava KD. Effect of shielding by trees on the frequency of lightning strokes to power lines. IEEE Trans Power Deliv 1988; 3(2): 724-32.

[28] Sakae M, Asakawa A, Ikesue K, Shindo T, Yokoyama S, Morooka Y. Investigation on lightning attachment manner by use of an experimental distribution line and a tree. Proceedings of IEEE/PES Transmission and distribution conference exhibition 2002: Asia Pacific 2002; 2217-22.

[29] McKechnie IS, Jandrell IR. A description and analysis of the path followed by a lightning current after a direct strike to a tree adjacent to a dwelling house. 29th International Conference on Lightning Protection. Uppsala, Sweden 2008. 